\title{
Immediate loading at single crowns and 2-unit bridges supported by implants installed in a healed alveolar bony ridge or immediately after tooth extraction. An experimental study in dogs
}

\author{
Viganò, Paolo ; Lang, Niklaus P ; Cesaretti, Gianfranco ; Bengazi, Franco ; Omori, Yuki ; Botticelli, Daniele
}

\begin{abstract}
To evaluate presumptive differences in osseointegration at implants installed in healed sites or extraction sockets, supporting either crowns or bridges that were functionally loaded or left unloaded. In six dogs, the mesial roots of the first mandibular molars were treated endodontically. Bilaterally, the teeth were hemisected, and the distal roots extracted. First and second mandibular premolars were extracted as well. After 3 months, the mandibular third and fourth distal roots were extracted after endodontic treatment of the mesial roots. Four implants were installed bilaterally, two in the healed sites corresponding to the second premolar and first molar regions, and two into the extraction sockets. Cobalt-chrome single crowns were prepared and installed in the two most anterior implants, and bridges at the two most posterior implants, bilaterally. A 3-unit bridge was applied to the premolars in the upper jaw only at the loaded sites. All prostheses had a flat occlusal surface and contacts in centric occlusion only at the loaded sites. Three months later, biopsies were retrieved for histological analysis. Higher levels of osseointegration and bone density were observed at the unloaded sites, both at implants installed in healed and post-extraction sites. However, only at implants installed in the post-extraction sites and supporting single crowns, the difference in bone-to-Implant contact was statistically significant. In implant installation immediately following extraction or delayed after three months, osseointegration and bone density were not affected by occlusal contact schemes.
\end{abstract}

DOI: https://doi.org/10.1111/joor.12702

Posted at the Zurich Open Repository and Archive, University of Zurich ZORA URL: https://doi.org/10.5167/uzh-159407

Journal Article

Accepted Version

Originally published at:

Viganò, Paolo; Lang, Niklaus P; Cesaretti, Gianfranco; Bengazi, Franco; Omori, Yuki; Botticelli, Daniele (2018). Immediate loading at single crowns and 2-unit bridges supported by implants installed in a healed alveolar bony ridge or immediately after tooth extraction. An experimental study in dogs. Journal of Oral Rehabilitation, 45(12):974-982.

DOI: https://doi.org/10.1111/joor.12702 
Article type : Original Article

Title: Immediate loading at single crowns and 2-unit bridges

supported by implants installed in a healed alveolar bony ridge or

immediately after tooth extraction. An experimental study in dogs.

Running Head: Immediate loading of implants

Article Category: Original Research

\section{Authors:}

Paolo Viganò, Niklaus P. Lang, Gianfranco Cesaretti, Franco Bengazi, Yuki Omori \& Daniele Botticelli

\section{Affiliations}

Paolo Viganò, Gianfranco Cesaretti, Franco Bengazi, Daniele Botticelli, ARDEC Academy, Rimini, Italy

Niklaus Peter Lang, Center for Dental Medicine, University of Zurich, Zurich, Switzerland; Professor emeritus University of Bern, Bern, Switzerland

This article has been accepted for publication and undergone full peer review but has not been through the copyediting, typesetting, pagination and proofreading process, which may lead to differences between this version and the Version of Record. Please cite this article as doi: $10.1111 /$ joor.12702

This article is protected by copyright. All rights reserved. 
Franco Bengazi, Daniele Botticelli, Faculty of Dentistry, University of Medical Science, La Habana, Cuba

Yuki Omori, Department of Oral Implantology, Osaka Dental University, Osaka, Japan and ARDEC Academy, Ariminum Odontologica, Rimini, Italy

\title{
Corresponding author:
}

Dott. Daniele Botticelli, BMBS, Dentist, Odont. dr. (PhD)

ARDEC Academy, Ariminum Odontologica srl

Viale Pascoli 67 - 47923 RIMINI (ITALY)

E-mail: daniele.botticelli@gmail.com

Tel.-Fax: +390541393444

\begin{abstract}
Objective: to evaluate presumptive differences in osseointegration at implants installed in healed sites or extraction sockets, supporting either crowns or bridges that were functionally loaded or left unloaded.
\end{abstract}

Material and Methods: In six dogs, the mesial roots of the first mandibular molars were treated endodontically. Bilaterally, the teeth were hemisected, and the distal roots extracted. First and second mandibular premolars were extracted as well. After three months, the mandibular third and fourth distal roots were extracted after endodontic treatment of the mesial roots. Four implants were installed bilaterally, two in the healed sites corresponding to the second premolar and first molar regions, and two into the extraction sockets. Cobaltchrome single crowns were prepared and installed in the two most anterior implants, and 
bridges at the two most posterior implants, bilaterally. A 3-unit bridge was applied to the premolars in the upper jaw only at the loaded sites. All prostheses had a flat occlusal surface and contacts in centric occlusion only at the loaded sites. Three months later, biopsies were retrieved for histological analysis.

Results: Higher levels of osseointegration and bone density were observed at the unloaded sites, both at implants installed in healed and post-extraction sites. However, only at implants installed in the post-extraction sites and supporting single crowns, the difference in bone-to-Implant contact was statistically significant.

Conclusions: In implant installation immediately following extraction or delayed after three months, osseointegration and bone density were not affected by occlusal contact schemes.

Key words: Animal Experimentation, Immediate Implant Loading, Histology, ImplantSupported Dental Prosthesis, Single-Tooth Implant, Dental Occlusion

\section{Background}

Occlusion and masticatory function were frequently discussed in recent years. ${ }^{1,2}$ It was shown that the dogs bite, pull, grab, and tear food using the anterior teeth in a centric occlusion, while they triturate and chew the food in the molar region, using both centric and lateral occlusion.

In a recently published paper, immediate and delayed load was studied in dogs. ${ }^{2}$ Two crowns supported by single implants in the premolar region, and a crown supported by two implants in the molar region were incorporated in both sides of the mandible within 48 hours, allowing immediate loading in one side of the mandible, and a delayed load in the opposite side. One implant was used as a non-loaded control. All crowns were manufactured trying to maintain the original shape and position of the extracted teeth to reproduce their function. 
Occlusal contacts were allowed bilaterally in centric occlusion at both natural and restored molars, and simultaneously at canines and incisors while, in lateral excursions, contacts were allowed between the lower first restored molar and fourth maxillary premolar (carnassial tooth). No contacts were allowed between the crowns in the premolar regions, similarly to the natural dentition. Despite the absence of premature contacts on the crowns in the molar regions, and the absence of occlusal contacts in the premolar regions, a higher rate of osseointegration and bone density were found at the loaded compared to the unloaded sites. Moreover, higher values of both parameters were found at the delayed loaded implants compared to the immediate loaded implants. This study showed an effect on osseointegration maintaining a functional load. However, analyzing a series of articles in which load was applied to implants in dogs, it appeared that only the centric occlusion was taken into consideration, and the reconstructions supported by implants installed in the mandible were placed carefully in contact with the prosthesis/ teeth of the upper jaw. However, no assessments of the occlusal contact of incisors and molars in centric occlusion and of the lateral movements were reported for both implants installed in healed ${ }^{3-5}$ or into extraction sockets. ${ }^{6-10}$ This, in turn, means that an excessive load on the implants supporting the prosthetic appliance cannot be excluded.

Based on these observations, it may be important to describe the osseointegration at implants installed in healed and post-extraction sites supporting fixed prostheses when the load is distributed also to the natural residual dentition.

Hence, the aim of the present experiment was to evaluate presumptive differences in osseointegration at implants installed in healed sites and extraction sockets supporting either crowns or bridges that are functionally loaded or left unloaded.

This article is protected by copyright. All rights reserved. 


\section{Material and methods}

The research protocol was submitted to and approved by the Ethical Committee of the University of Medical Sciences, School of Dentistry, La Habana, Cuba (protocol No. 04/2009, approved on May 20, 2009). The present study followed the ARRIVE checklist for Animal Research: Reporting In Vivo Experiments (https://www.nc3rs.org.uk/arriveguidelines) and the principles of the $3 R^{s}$ (Replacement, Reduction and Refinement) were applied.

\section{Experimental animals}

Six Beagle dogs of about $10.5 \mathrm{Kg}$ of weight and about one year old were used. The dogs were provided by the CENPALAB (Centro Nacional para la Producción de Animales de Laboratorio) and maintained in kennels at the University of Medical Sciences of La Habana, Cuba. The animals were feed of food for dogs. Free access to water was always allowed.

\section{Clinical procedures}

A scheme of the protocol and the timeline are described in Figure 1. Before each surgery, atropine $0.02 \mathrm{mg} / \mathrm{kg}$ (Mayne Pharma, Napoli, Italia), metedomidine $0.04 \mathrm{mg} / \mathrm{kg}$ (Medetor® ,Virbac, Glattbrugg, Switzerland) and ketamine-50 5 mg/kg (Liorad, La Habana, Cuba) were provided. The anesthesia was maintained with $2.5 \%$ Isoflurane-Vet ${ }^{\circledR}$ (Merial, Merial Tolosa, France). Local anesthesia was injected in the regions of the experiment. During the surgery, tramadol $\AA 2 \mathrm{mg} / \mathrm{Kg} \quad($ Altadol $\AA$, Formevet, Milan, Italy) and amoxicillin $\AA 10 \mathrm{mg} / \mathrm{Kg}$ (Convenia®, Pfizer, U.S.A.) were also administered.

\section{Surgical and endodontic session}

At the first surgery (Figure $2 \mathrm{~A}$ ), the mesial root of the first mandibular molars were endodontically treated bilaterally using an Endopocket ${ }^{\circledR}$ device with Mtwo® inserts (Sweden \& Martina, Due Carrare, Padua, Italy). Epfill $\circledast$ was also used to seal the canal with guttapercha (Sweden \& Martina, Due Carrare, Padua, Italy). The teeth were subsequently 
hemisected, and the distal roots extracted in both sides of the mandible together the first and second mandibular premolars. After 3 months of healing, similar endo-treatments were also performed to the mesial roots of P3 and P4, bilaterally. Full thickness flaps were elevated from the first premolar to the first molar regions, bilaterally, and the third and fourth premolars were hemisected and the distal roots extracted.

Recipient sites were prepared inside the distal alveoli of 3P3 and 4P4 and in the edentulous healed regions of $2 \mathrm{P} 2$ and $1 \mathrm{M} 1$ (area of the distal root). Four implants, $7 \mathrm{~mm}$ long and 3.3 $\mathrm{mm}$ in diameter (Premium, Sweden \& Martina, Due Carrare, PD, Italy), were installed in each side of the mandible in the healed sites of $2 \mathrm{P} 2$ and $1 \mathrm{M} 1$ as well as in the distal extraction sockets of 3P3 and 4P4. The coronal margin of the rough surface was placed at the level of the buccal bone crest. All implants had a ZirTi® surface and a polished neck of $0.3 \mathrm{~mm}$ of height. The final insertion torque was measured and, immediately after the installation, RFA values were obtained using the Osstell® Mentor (Osstell, Gothenburg, Sweden).

The residual mesial part of the crown of the molars were reduced in height just above the mucosal margin not to interfere with the prosthetic reconstruction. Transfers were applied on the implants (Figure 2B) and a single-phase impression was taken using polyvinyl siloxane (Sky light and Sky medium, Sweden \& Martina, Due Carrare, PD, Italy). Healing abutments were affixed temporarily and the flaps sutured around the healing abutments with resorbable sutures (Vicryl 4-0; Johnson \& Johnson, Medical S.p.A., Pomezia, Roma). Subsequently, in the same session, maxillary second, third and fourth premolars were prepared only at the randomly assigned loaded sites. Impressions were taken using polyvinyl siloxane.

This article is protected by copyright. All rights reserved. 


\section{Prosthetic session}

The implants installed in the regions of the second and third premolars were used for single crowns rehabilitation only at the loaded sites. In contrast, the two distal implants placed in the alveoli of the fourth premolars, and in the healed region of the first molars were used for bridge reconstructions, bilaterally.

Within 48 hours, for the implant sites, single crowns and bridges made of cobalt-chrome were manufactured and prepared with flat occlusal surfaces. The single crowns were screwed to the implants in the region of the second and third premolars of the loaded sites (Figure $2 \mathrm{C}$ ), while healing abutments were kept in the premolars of the unloaded site. The two-unit bridges were screwed to the implants located in the regions of $4 \mathrm{P} 4$ and $1 \mathrm{M} 1$, bilaterally. For the maxillary sites, 3-unit units bridges made also of cobalt-chrome were manufactured and prepared with flat occlusal surfaces and fixed with a glass ionomer cement (Fuji I, GC Corporation, Tokyo, Japan) at the loaded sites (Figure 2C). Using articulating papers (200 micron, Baush, Nashua, NH, U.S.A.), the centric occlusion contacts and the contacts in the lateral movements were checked at the prosthetic reconstructions of the loaded sites both in the premolar and molar regions, as well as at the incisors groups and, bilaterally, at the second molars. At the control (non-loaded) sites, occlusal contacts were eliminated by grinding the occlusal surface of the prostheses (Figure 2D), while the abutments placed on the premolars at the unloaded sites showed no contact at all.

\section{Maintenance}

Antibiotics (Amoxicillin ${ }^{\circledR} 20$ mg/Kg per diem; Convenia ${ }^{\circledR}$, Pfizer, U.S.A.) and analgesics (Tramadol 2mg/kg per diem; Altadol $\circledast$, Formevet, Milan, Italy) were administered for 5 days after each surgery. The wounds were inspected daily during the first week of healing to identify possible complications and to clean the regions of the experiment. During the following periods of healing, inspections and cleaning were performed twice a week. The sutures were removed after 2 weeks while the occlusal contacts were checked every month. 
The animals were euthanized 3 months after the loading using sodium heparin $1.000 \mathrm{IU}$, atropine $0.02 \mathrm{mg} / \mathrm{Kg}, 1 \mathrm{mg} / \mathrm{kg}$ of xylazine (Rompun®, Kiel, Germany), $5 \mathrm{mg} / \mathrm{kg}$ of ketamine (Liorad, La Habana, Cuba), and 25 mEq of potassium chloride i.v. (Aica, La Habana, Cuba) to arrest the heart. A perfusion with $4 \%$ formaldehyde solution was performed through the carotid arteries.

\section{Histological preparation}

Each block containing one implant was first dehydrated in a series of graded ethanols and then embedded into resin (Technovit@ 7200 VLC, Kulzer, Friedrichsdorf, Germany). Each implant inside the block was identified and cut in a buccal-lingual direction following its long axis using a band saw mounted in a precision slicing machine (Exakt $\AA$, Apparatebau, Norderstedt, Germany). One central section was reduced to a thickness of about $50-60 \mu m$ using a cutting-grinding machine (Exakt®, Apparatebau, Norderstedt, Germany) and stained with Stevenel's blue and alizarin red.

\section{Histological evaluations}

Histological evaluations were performed using an Eclipse Ci microscope (Nikon Corporation, Tokyo, Japan) and a digital video camera (Digital Sight DS-2Mv, Nikon Corporation, Tokyo, Japan) connected to a computer. Measurements were carried out with the software NISElements D 4.10 (Laboratory Imaging, Nikon Corporation, Tokyo, Japan).

The following landmarks were defined (Figure 3): IS, implant shoulder; $\mathrm{M}$, coronal margin of the rough surface; $\mathrm{C}$, top of the bone crest; $\mathrm{B}$, most coronal contact of the bone to the implant; T, standardized limit between the cortical and marrow compartments. The distance between IS and C (IS-C) and IS and B (IS-B) were evaluated at x100 magnification. The distances $\mathrm{M}-\mathrm{C}$ and $\mathrm{M}-\mathrm{B}$ were obtained subtracting the height of the neck $(0.8 \mathrm{~mm})$ from IS-C and IS-B, respectively. The percentages of mineralized bone (bone-to-implant contact; $\mathrm{MBIC} \%$ ) in contact with the implant surface at a magnification of $\mathrm{x} 100$, and of mineralized 
bone density at a magnification of $x 200$ were measured both in the cortical and marrow regions. The cortical region was conventionally included between the most coronal contact of the bone to the implant surface and the initial part of the first threads. The marrow region conventionally included all threads and excluded the apex of the implant. To perform the morphometric analysis, a lattice with squares of $50 \mu \mathrm{m}$ in dimensions was superposed over the tissues at a magnification of x200 (Schroeder \& Münzel-Pedrazzoli 1973). An area of about $0.4 \mathrm{~mm}$ aside the implant was evaluated.

\section{Randomization and data analysis}

The assignment for immediately loaded and unloaded treatment to the left or right sides of the mandible was randomized (www.randomization.com) by a subject not involved in the surgery (DB). All surgical and prosthetic procedures were performed by an expert operator (PV). The treatments were revealed by DB to PV after the positioning of the implants. The histological measurements were performed by a subject (GC) that was not informed about the allocation on the histological slides. The intra-class correlation coefficient was $>0.9$ for the histological assessments. Six animals represented each period of healing $(n=6)$. The primary outcome variable was total mineralized $\mathrm{MBIC} \%$ and bone density\% and mean values, standard deviations and confidence intervals were calculated. The peri-implant hard tissues dimensions (M-B and $\mathrm{M}-\mathrm{C}$ ) were used as secondary variables. Mean values and standard deviations were calculated for the other outcome variables.

Differences between immediately loaded (test) and unloaded (control) sites were analyzed with a IBM SPSS Statistics software (IBM Inc., Chicago, IL, USA) using a Wilcoxon signed rank test. The level of significance was set at $\alpha=0.05$. As an exploratory aim, differences were also assessed between the healed and post-extraction sites.

This article is protected by copyright. All rights reserved. 


\section{Results}

\section{Clinical evaluation}

The final insertion torque was $\geq 35 \mathrm{Ncm}$ at all implants both at the healed and extraction sockets sites. The RFA values measured at P2, P3, P4 and M1 sites were $69.6 \pm 5.5,65 \pm 3.7,57.6 \pm 10.7,68.4 \pm 6.8$ ISQ in the loaded group, and $70.8 \pm 5.1$, $61.6 \pm 5.7,53.8 \pm 12.6,68.6 \pm 6.6$ ISQ in the unloaded group, respectively. No statistically significant differences were found between loaded and unloaded sites. At the clinical evaluations, no apparent occlusal changes were observed and no complications were found.

\section{Histological evaluations}

All implants were available for the histological assessments (Figures 4A-D, 5A-D). Mean values and standard deviations of primary and secondary outcomes are reported in Tables 1, 2, and 3. The $95 \%$ confidence interval $(\mathrm{Cl})$ of the difference of means was calculated for primary variables and are reported in Table 4.

\section{Single crowns}

At the healed sites, Tot-MBIC $\%$ was $70.4 \pm 8.1 \%$ at the loaded implants and $73.1 \pm 9.8 \%$ at the unloaded implants. The total mineralized bone density percentage (Tot-Density \%) was $76.8 \pm 10.8 \%$ and $77.2 \pm 9.4 \%$, respectively (Table 1 ).

At the post-extraction sites of the single crown group, the Tot-MBIC\% was $72.9 \pm 6.5 \%$ at the loaded implants and $80.1 \pm 8.7 \%$ at the unloaded implants. The Tot-Density was $76.2 \pm 8.9 \%$ and $76.6 \pm 6.1 \%$, respectively (Table 1 ). Only the Tot-MBIC\% at the post-extraction sites presented a difference that was statistically significant $(p<0.05)$.

This article is protected by copyright. All rights reserved. 
The mean distances $M-C$ ranged between about $0.6-0.7 \mathrm{~mm}$ in both groups while $M-B$ ranged between 0.7-1.2 $\mathrm{mm}$ (Table 2). No statistically significant differences were found for M-C and M-B values between loaded and unloaded sites.

\section{2-unit bridges}

The Tot-MBIC\% at the healed sites was $65.0 \pm 16.3 \%$ and $73.0 \pm 6.4 \%$ at the loaded and unloaded implants, respectively. The Tot-Density\% was $78.6 \pm 12.4 \%$ at the loaded sites and $83.0 \pm 7.2 \%$ at the unloaded sites (Table 3 ).

The Tot-MBIC\% at the post-extraction sites was $65.9 \pm 23.7 \%$ and $72.4 \pm 11.7 \%$ at the loaded and unloaded implants, respectively. The Tot-Density $\%$ was $75.9 \pm 7.2 \%$ and $76.9 \pm 9.2 \%$, respectively. None of the differences was statistically significant (Table 3).

The mean distances $\mathrm{M}-\mathrm{C}$ ranged between $0.3-1.0 \mathrm{~mm}$ in both groups while $\mathrm{M}-\mathrm{B}$ ranged between 0.9-1.4 mm (Table 2). No statistically significant differences were found for $M-C$ and M-B values between loaded and unloaded sites.

\section{Discussion}

The aim of the present experiment was to evaluate presumptive differences in osseointegration at implants installed in healed sites and extraction sockets supporting crowns and bridges either functionally loaded or left unloaded.

The physiologic chewing in the dogs includes two movements, a vertical and a lateral, instead of the four movements performed by humans. ${ }^{1,2}$ It seems unlikely to reproduce correctly in dogs a load applied to the chewing elements in humans. Until now, most of the studies focused on occlusal contacts of flat surfaces in centric occlusion. In the present study, prosthetic reconstructions with flat surfaces have been applied in both the maxilla and mandible at the loaded sites. Conversely, in the unloaded sites, the prosthetic 
reconstructions with flat occlusal surfaces were used only on the implants in the mandible while in the maxilla no modifications were performed to the natural teeth. In these unloaded sites of the mandible, the occlusal surfaces of the prosthesis was reduced to eliminate any possible contacts with the opposing jaw. However, the reproduction of chewing with flat surfaces does not correspond to the physiologic function in the dog, ${ }^{1,2}$ and may affect the chewing efficacy. In the unloaded sites, no adjustments were made to the teeth of the maxilla. It may be speculated that this may have contributed to provide a higher degree of chewing efficacy possibly leading to a heavier use of this side of the mouth compared to the contralateral side.

Positive effects of functional load on osseointegration have been reported in several clinical studies. ${ }^{11-13}$ However, in another clinical study involving 13 volunteers, ${ }^{14}$ no statistically significant differences could be found between loaded and unloaded sites after either 1 or 3 months.

In a recent experiment, ${ }^{15}$ three implants were installed in the premolar region on both sides of the mandible either with $S L A \circledast$ or with $S L A c t i v e{ }^{\circledR}$ moderately rough surfaces. One implant served as a positive control and was loaded in a proper stable occlusal scheme, while one implant was not loaded at all and served as a negative control. The test implant was subjected to severe excessive load by constructing premature contacts on a cantilever. No significant differences were detected between baseline and 24-weeks or between groups for all clinical parameters. Likewise, linear radiographic measurements yielded similar results for SLA® and SLActive® implants. SLA® excessively loaded implants yielded a statistically significant gain on peri-implant bone density over all other groups $(p=0.012)$. The radiographic results were confirmed by histological analysis. It was concluded that excessive occlusal load applied to implants (SLA® or SLActive®) restored with cantilevers did not cause loss of osseointegration or significant changes in their clinical outcomes. However, an early excessive occlusal load (premature contacts) on SLA® implants promoted a gain in peri-implant bone density.

This article is protected by copyright. All rights reserved. 
The present experimental study also showed some contradictory results when compared to for instance a dog experiment. ${ }^{3}$ In that study, three months after the extraction of all mandibular premolars, four implants of two different systems were installed on each side of the mandible. After three months, prostheses with flat occlusal surfaces contacts in centric occlusion were constructed for the three distal implants in the mandible and for the maxillary canine/ premolars, bilaterally. The most mesially located implant was left unloaded and served as control in both sides of the mandible. After 10 months of function, higher levels of bone-to-implant contact were obtained at the loaded sites compared to the control sites. However, no statistical significant differences in bone density were obtained between test and control sites.

In another experiment in dogs, ${ }^{5}$ all premolars and first molars were extracted, bilaterally. After four months, two implants were installed bilaterally and the second and third maxillary premolars were prepared for prostheses only at the loaded sites. Within 24 hours, single crowns were applied to the implants at the loaded sites and a two-unit bridge was cemented to the premolars in the opposing maxillary jaw. Occlusal contacts in centric occlusion were revealed. At the contralateral sides of the mandible, only healing abutments were installed avoiding direct occlusal contacts with the teeth of the opposing maxillary sites. Osseointegration and bone density were found to a higher degree at the immediately loaded compared to the unloaded sites. In the light of the results reported in other studies, ${ }^{1,2}$ the masticatory function may have favored the chewing at the loaded implants maybe due to premature contacts at these sites.

Overload may affect osseointegration or bone density around implants, as well as the survival rate of implants, as reported in various studies in which premature contacts were incorporated in the prosthesis. ${ }^{16-19}$ In a study in monkeys, ${ }^{16}$ premature contacts were produced on teeth and implants. While the teeth intruded over time, the implants could bear the load by a thickening and a remodeling of the bone surrounding the implants. In another study in monkeys, ${ }^{17}$ superstructure with excessive occlusal height of 100 microns were 
placed in function for 1 to 4 weeks. No bone loss was observed for the excessive load. In another study in monkeys, ${ }^{18}$ an overload prolonged over time resulted in a loss of 5 out of 8 implants after 4.5 to 15.5 months of function. It has to be realized that those implants that were lost were installed in very loosely trabecular bone (Type IV) and hence, it is likely that the osseointegration was broken by the heavy occlusal forces. In an experimental study in dogs, mandibular premolars and molars were extracted and, after 3 months, four implants were installed each side of the mandible. ${ }^{19}$ After 6 months of healing, single crowns were incorporated onto the implants in one side of the mandible, while the contralateral side was left unloaded. The crowns presented at least $3 \mathrm{~mm}$ of hyper-contact so that neither the abutments at the control sites nor the frontal teeth had any occlusal contact in centric occlusion. No molars were left in the mandible to support the occlusion. After 8 months, no differences in bone density were seen between loaded and unloaded implant sites. It can be argued that dogs rarely close the mouth in centric occlusion, not even during deglutition. ${ }^{1}$ Moreover, dogs chew and triturate food in the molar region, using both centric and lateral occlusion. It may be argued if dogs were able to use such long crowns to chew and so to really apply an overload.

Conflicting results on the outcomes of overload in dogs have been confirmed in a review in which it was however concluded that an overload might lead to an increase in bone density. ${ }^{20}$

In the present study, when the total bone was considered, no major differences were seen in osseointegration or bone density between implants installed in healed or post-extraction sites. These outcomes are in agreement with other experimental studies that evaluated the healing at implants installed in post-extraction or healed sites, with or without loading. ${ }^{6,10,21}$

This article is protected by copyright. All rights reserved. 
An important limitation of the present study is that the human occlusion and function cannot be realistically reproduced in dogs because in dogs only two movements, a vertical and a lateral, are allowed while the humans use four movements. Important differences are also related to tooth shape and deglutition. The low number of animals used may also represent a limit.

In conclusion, in implant installation immediately following tooth extraction or delayed after three months, osseointegration and bone density were not affected by occlusal contact schemes. Peri-implant hard tissues dimensions appeared not to be influenced as well by load.

\section{Acknowledgements}

Sweden \& Martina SRL, Due Carrare, Padova, Italia provided funds to Ariminum Odontologica s.r.l., Rimini, Italy to cover part of the costs for the experiment. The remaining costs were covered by ARDEC Academy, Ariminum Odontologica s.r.l., Rimini, Italy. The Scientific support by ARDEC Academy, Ariminum Odontologica s.r.l., Rimini, Italy and the Clinical Research Foundation (CRF) for the Promotion of Oral Health, $\mathrm{CH}-3855$ Brienz, Switzerland is highly appreciated.

TePe Munhygienprodukter AB, Malmö, Sweden provided the oral hygiene products.

Dr. Daniele Botticelli declares to be co-owner of Ariminum Odontologica and to be the principal investigator of ARDEC Academy. All the other authors declare no conflict of interest regarding this study.

This article is protected by copyright. All rights reserved. 


\section{References}

1. Passerini A, Vigano P, Cesaretti G, Rodríguez Sosa VM, Domínguez López HA, Pérez M, et al. Nuevo enfoque de la dinámica masticatoria en el perro (New point of view of masticatory dynamic in dog) Rev Electrón vet. 2017;18 (02):1-13.

2. Cesaretti G, Lang NP, Viganò P, Bengazi F, Apaza Alccayhuaman KA, Botticelli D. Immediate and delayed loading of fixed dental prostheses supported by single or two splinted implants: A histomorphometric study in dogs. J Oral Rehabil. 2018 Apr;45(4):308-316.

3. Berglundh T, Abrahamsson I, Lindhe J. Bone reactions to longstanding functional load at implants: an experimental study in dogs. J Clin Periodontol. 2005; 32(9):925-932.

4. Calvo-Guirado JL, Aguilar-Salvatierra A, Gomez-Moreno G, Guardia J, Delgado-Ruiz RA, Val JE. Histological, radiological and histomorphometric evaluation of immediate vs. nonimmediate loading of a zirconia implant with surface treatment in a dog model. Clin Oral Implants Res. 2014;25(7):826-830.

5. Rea M, Botticelli D, Ricci S, Soldini C, González GG, Lang NP. Influence of immediate loading on healing of implants installed with different insertion torques--an experimental study in dogs. Clin Oral Implants Res. 2015;26(1):90-95.

6. Blanco J, Liñares A, Villaverde G, Pérez J, Muñoz F. Flapless immediate implant placement with or without immediate loading: a histomorphometric study in beagle dog $\mathrm{J}$ Clin Periodontol. 2010;37(10):937-942.

7. Blanco J, Carral C, Liñares A, Pérez J, Muñoz F. Soft tissue dimensions in flapless immediate implants with and without immediate loading: an experimental study in the beagle dog. Clin Oral Implants Res. 2011;23(1):70-75.

8. Blanco J, Liñares A, Pérez J, Muñoz F. Ridge alterations following flapless immediate implant placement with or without immediate loading. Part II: a histometric study in the Beagle dog. J Clin Periodontol. 2011;38(8):762-770.

9. Blanco J, Mareque S, Liñares A, Pérez J, Muñoz F, Ramos I. Impact of immediate loading on early bone healing at two-piece implants placed in fresh extraction sockets: an experimental study in the beagle dog. J Clin Periodontol. 2013;40(4):421-429.

10. Mainetti T, Lang NP, Bengazi F, Sbricoli L, Soto Cantero L, Botticelli D. Immediate loading of implants installed in a healed alveolar bony ridge or immediately after tooth extraction: an

This article is protected by copyright. All rights reserved. 
experimental study in dogs. Clin Oral Implants Res. 2015;26(4):435-441.

11. Rocci A, Martignoni M, Burgos PM, Gottlow J, Sennerby L. Histology of retrieved immediately and early loaded oxidized implants: light microscopic observations after 5 to 9 months of loading in the posterior mandible. Clin Implant Dent Relat Res. 2003;5 Suppl 1:88-98.

12. Degidi M, Piattelli A, Shibli JA, Perrotti V, lezzi G. Bone formation around immediately loaded and submerged dental implants with a modified sandblasted and acid-etched surface after 4 and 8 weeks: a human histologic and histomorphometric analysis. Int $\mathrm{J}$ Oral Maxillofac Implants. 2009;24(5):896-901.

13. Yonezawa D, Piattelli A, Favero R, Ferri M, lezzi G, Botticelli D. Bone Healing at Functionally Loaded and Unloaded Screw-Shaped Implants Supporting Single Crowns: A Histomorphometric Study in Humans. Int J Oral Maxillofac Implants. 2018 Jan/Feb;33(1):181187.

14. Donati M, Botticelli D, La Scala V, Tomasi C, Berglundh T. Effect of immediate functional loading on osseointegration of implants used for single tooth replacement. A human histological study. Clin Oral Implants Res. 2013;24(7):738-745.

15. Lima LA, Chambrone L, Bosshardt DD, Araújo MG, Lang NP. (2018) Excessive occlusal load on chemically modified and moderately rough titanium implants restored with cantilever reconstructions. An experimental study in dogs. Clinical Oral Implants Research 29: in press.

16. Ogiso M, Tabata T, Kuo PT, Borgese D. A histologic comparison of the functional loading capacity of an occluded dense apatite implant and the natural dentition. J Prosthet Dent. 1994;71(6):581-588

17. Miyata $\mathrm{T}$, Kobayashi $\mathrm{Y}$, Araki $\mathrm{H}$, Ohto $\mathrm{T}$, Shin $\mathrm{K}$. The influence of controlled occlusal overload on periimplant tissue. Part 3: A histologic study in monkeys. Int J Oral Maxillofac Implants. 2000;15(3):425-431.

18. Isidor F. Loss of osseointegration caused by occlusal load of oral implants. A clinical and radiographic study in monkeys. Clin Oral Implants Res. 1996;7(2):143-152.

19. Heitz-Mayfield LJ, Schmid B, Weigel C, Gerber S, Bosshardt DD, Jönsson J, et al. Does excessive occlusal load affect osseointegration? An experimental study in the dog. Clin Oral Implants Res. 2004;15(3):259-268.

20. Chambrone L, Chambrone LA, Lima LA. Effects of occlusal overload on peri-implant tissue

This article is protected by copyright. All rights reserved. 
health: a systematic review of animal-model studies. J Periodontol. 2010 Oct;81(10):1367-78.

21. Mainetti T, Lang NP, Bengazi F, Favero V, Soto Cantero L, Botticelli D. Sequential healing at implants installed immediately into extraction sockets. An experimental study in dogs. Clin Oral Implants Res. 2016 Jan;27(1):130-8.

\section{Legends}

Figure 1. Drawing representing scheme and timeline of the protocol applied.

Figure 2. (A) Occlusion in centric occlusion before surgery. Note the intercuspal distance among premolars of the upper and lower jaws. (B) Transfers applied to the unloaded implants in the fourth premolar and first molar regions. Healing abutments applied at implants in the second and third premolar regions. (C) Loaded sites. Bridge and crowns attached to the implants in the first molar/ fourth premolar regions and in the second/ third premolar regions, respectively. Contacts in centric occlusion were obtained with the bridge cemented to the maxillary premolars. (D) Unloaded site. No contacts between the bridge and the teeth of the opposing jaw were allowed.

Figure 3. Image illustrating the landmarks used for histological measurements. (IS) implant shoulder; (M) coronal margin of the rough surface; $(\mathrm{C})$ top of the bone crest; (B) most coronal contact of the bone to the implant; $(\mathrm{T})$ standardized limit between the cortical and marrow compartments.

Figure 4. Ground sections representing the healing of implants supporting single crowns. (A) Healed loaded site; (B) healed unloaded site; (C) post-extraction loaded site; (D) post-extraction unloaded site. The photomicrographs were original grabbed at $\mathrm{x} 20$ magnification. Stevenel's blue and alizarin red stain.

Figure 5. Ground sections representing the healing of implants supporting Bridges. (A) Healed loaded site; (B) healed unloaded site; (C) post-extraction loaded site; (D) post-extraction unloaded site. The photomicrographs were original grabbed at x20 magnification. Stevenel's blue and alizarin red stain.

This article is protected by copyright. All rights reserved. 
Table 1. Mineralized bone-to-implant contact percentage (MBIC \%) and mineralized bone density percentage (DENSITY \%) at the single crown sites. Mean $\pm S D$.

\begin{tabular}{|c|c|c|c|c|c|c|c|}
\hline \multicolumn{2}{|c|}{$n=6$} & \multicolumn{3}{|c|}{ MBIC \% } & \multicolumn{3}{|c|}{ DENSITY \% } \\
\hline & & $\begin{array}{l}\text { Cortical } \\
\text { region }\end{array}$ & $\begin{array}{l}\text { Marrow } \\
\text { region }\end{array}$ & Total & $\begin{array}{l}\text { Cortical } \\
\text { region }\end{array}$ & $\begin{array}{l}\text { Marrow } \\
\text { region }\end{array}$ & Total \\
\hline \multirow{2}{*}{ HEALED } & LOADED & $73.5 \pm 6.2$ & $70.3 \pm 8.3$ & $70.4 \pm 8.1$ & $83.1 \pm 14.5$ & $75.9 \pm 11.0$ & $76.8 \pm 10.8$ \\
\hline & UNLOADED & $76.2 \pm 10.3$ & $73.1 \pm 11.0$ & $73.1 \pm 9.8$ & $87.7 \pm 6.7$ & $75.1 \pm 10.9$ & $77.2 \pm 9.4$ \\
\hline \multirow{2}{*}{ POST-EXTRACTION } & LOADED & $67.4 \pm 16.1$ & $73.2 \pm 6.3^{*}$ & $72.9 \pm 6.5^{*}$ & $87.9 \pm 8.7$ & $75.8 \pm 9.1$ & $76.2 \pm 8.9$ \\
\hline & UNLOADED & $82.5 \pm 13.1$ & $80.2 \pm 9.5^{*}$ & $80.1 \pm 8.7^{*}$ & $85.5 \pm 11.6$ & $75.0 \pm 6.0$ & $76.6 \pm 6.1$ \\
\hline
\end{tabular}

$=p<0.05$ between loaded and unloaded sites. $\#=p<0.05$ between healed and post-extractive sites.

This article is protected by copyright. All rights reserved. 
Table 2. Peri-implant hard tissues dimensions at the buccal aspects of single crowns and bridge sites. Mean $\pm S D$ in millimeters. $M$, coronal margin of the rough surface; $C$, top of the bone crest; $B$, most coronal contact of the bone to the implant.

\begin{tabular}{|c|c|c|c|c|c|}
\hline \multirow{2}{*}{\multicolumn{2}{|c|}{$\begin{array}{c}n=6 \\
\text { SITES }\end{array}$}} & \multicolumn{2}{|c|}{ SINGLE CROWNS } & \multicolumn{2}{|c|}{ BRIDGES } \\
\hline & & $\mathrm{M}-\mathrm{C}$ & $M-B$ & M-C & M-B \\
\hline \multirow{2}{*}{ HEALED } & LOADED & $0.7 \pm 0.5$ & $0.9 \pm 0.7$ & $0.4 \pm 0.4$ & $1.1 \pm 0.9$ \\
\hline & UNLOADED & $0.7 \pm 0.5 \#$ & $0.7 \pm 0.6$ & $0.3 \pm 0.2$ & $0.9 \pm 0.7$ \\
\hline \multirow[t]{2}{*}{ POST-EXTRACTION } & LOADED & $0.6 \pm 0.4$ & $1.2 \pm 0.5$ & $0.5 \pm 0.9$ & $0.9 \pm 0.8$ \\
\hline & UNLOADED & $0.6 \pm 0.9 \#$ & $0.8 \pm 0.7$ & $1.0 \pm 0.5$ & $1.4 \pm 0.4$ \\
\hline
\end{tabular}

$p<0.05$ between loaded and unloaded sites. \# $=p<0.05$ between healed and post-extractive site

This article is protected by copyright. All rights reserved. 
Table 3. Mineralized bone-to-implant contact percentage (MBIC \%) and mineralized bone density percentage (DENSITY \%) at the bridge sites. Mean \pm SD.

\begin{tabular}{lccccccc}
\hline \multicolumn{1}{c}{$\begin{array}{c}\text { S=6 } \\
\text { SITES }\end{array}$} & $\begin{array}{c}\text { Cortical } \\
\text { region }\end{array}$ & $\begin{array}{c}\text { MBIC } \% \\
\text { region }\end{array}$ & Total & $\begin{array}{c}\text { Cortical } \\
\text { region }\end{array}$ & $\begin{array}{c}\text { MENSITY \% } \\
\text { region }\end{array}$ & Total \\
HEALED & LOADED & $64.5 \pm 19.4$ & $65.0 \pm 16.4$ & $65.0 \pm 16.3$ & $86.4 \pm 10.3$ & $75.8 \pm 17.7$ & $78.6 \pm 12.4$ \\
\multirow{2}{*}{ POST-EXTRACTION } & UNLOADED & $63.9 \pm 14.5^{\#}$ & $74.7 \pm 5.4$ & $73.0 \pm 6.4$ & $83.0 \pm 6.8$ & $82.9 \pm 7.6^{\#}$ & $83.0 \pm 7.2$ \\
& LOADED & $75.8 \pm 14.8$ & $64.9 \pm 25.4$ & $65.9 \pm 23.7$ & $83.8 \pm 6.1$ & $74.3 \pm 7.3$ & $75.9 \pm 7.2$ \\
& UNLOADED & $76.3 \pm 7.3^{\#}$ & $72.1 \pm 12.2$ & $72.4 \pm 11.7$ & $84.0 \pm 5.4$ & $75.5 \pm 11.0^{\#}$ & $76.9 \pm 9.2$ \\
\hline
\end{tabular}

This article is protected by copyright. All rights reserved. 
Table 4. 95\% confidence interval (CI) of the difference of means for mineralized bone-to-implant contact percentage (MBIC \%) and mineralized bone density percentage (DENSITY \%). Values in millimeters.

\begin{tabular}{lccccc}
\hline \multicolumn{1}{c}{$\mathbf{n}=\mathbf{6}$} & \multicolumn{2}{c}{ SINGLE CROWNS } & \multicolumn{2}{c}{ BRIDGES } \\
\multicolumn{1}{c}{ SITES } & MBIC\% & DENSITY\% & MBIC\% & DENSITY\% \\
& & $-2.7 \pm 14.6$ & $-0.4 \pm 15.8$ & $-8.0 \pm 16.3$ & $-4.4 \pm 11.4$ \\
HEALED & $-14.4 ; 9.0$ & $-13.0 ; 12.2$ & $-21.0 ; 5.0$ & $-13.6 ; 4.7$ \\
& \multirow{2}{*}{ P-VALUE } & 0,668 & 0,954 & 0,283 & 0,387 \\
& & $-7.2 \pm 4.6 *$ & $-0.3 \pm 9.8$ & $-6.5 \pm 26.1$ & $-1.0 \pm 9.3$ \\
& & $-10.9 ;-3.6$ & $-8.2 ; 7.5$ & $-27.4 ; 14.5$ & $-8.4 ; 6.4$ \\
& & 0,046 & 0,753 & 0,572 & 0,804 \\
\hline
\end{tabular}

$p<0.05$ between loaded and unloaded sites. $\#=p<0.05$ between healed and post-extractive sites.

This article is protected by copyright. All rights reserved. 

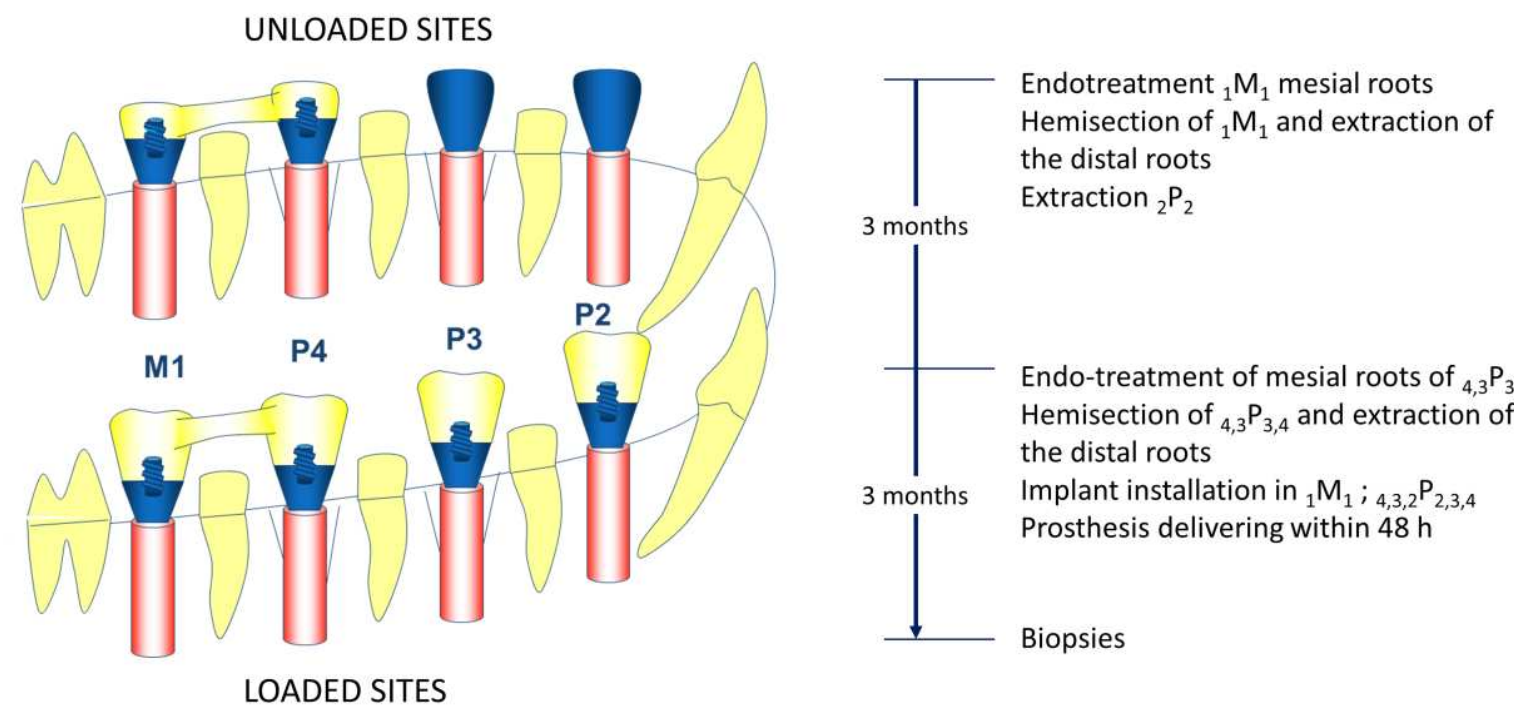

Endotreatment ${ }_{1} \mathrm{M}_{1}$ mesial roots Hemisection of ${ }_{1} M_{1}$ and extraction of the distal roots Extraction ${ }_{2} \mathrm{P}_{2}$

Endo-treatment of mesial roots of ${ }_{43} \mathrm{P}_{3,4}$ Hemisection of ${ }_{4,3} \mathrm{P}_{3,4}$ and extraction of e distal roots

Implant installation in ${ }_{1} \mathrm{M}_{1} ;{ }_{4,3,2} \mathrm{P}_{2,3,4}$

Biopsies

LOADED SITES
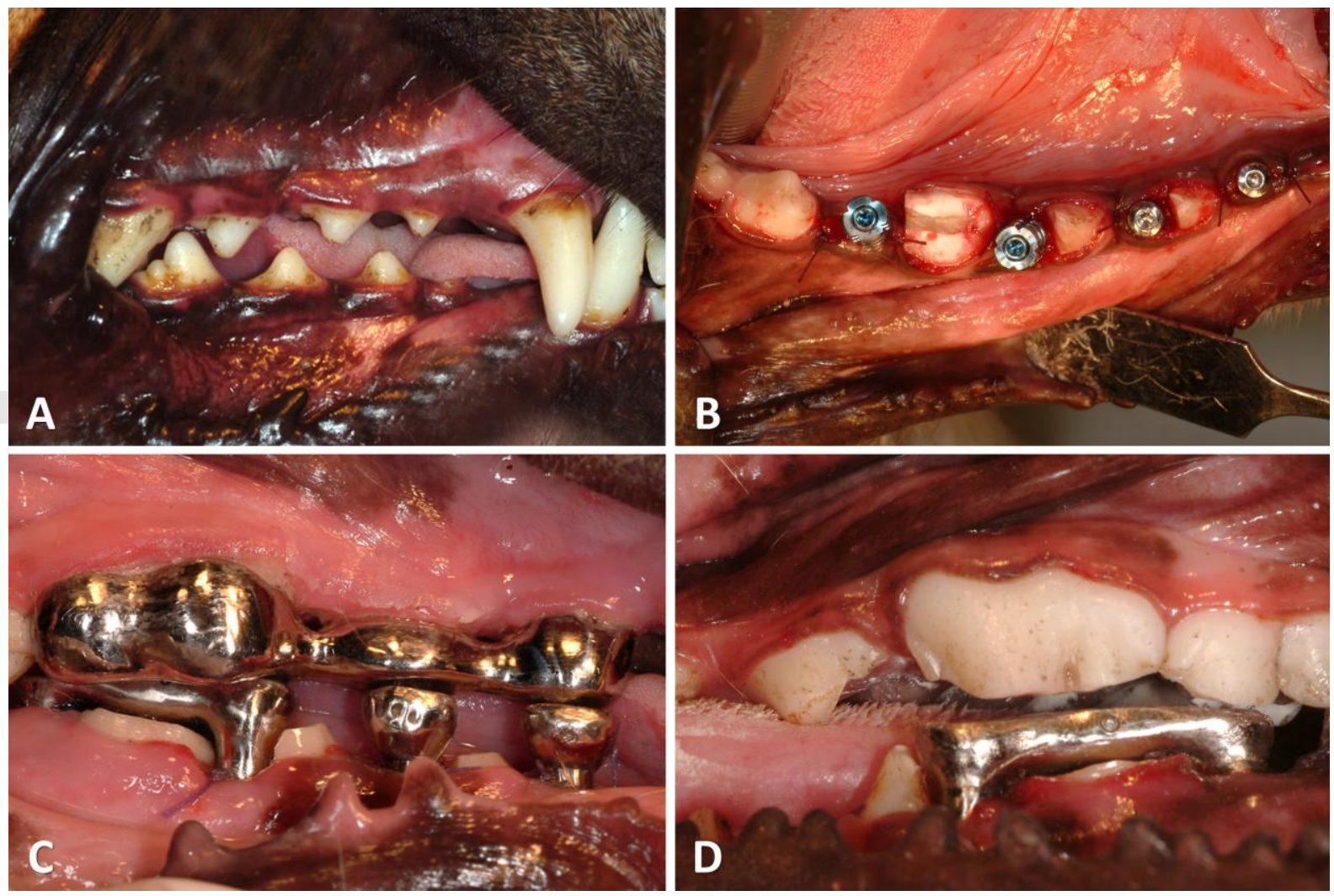

This article is protected by copyright. All rights reserved. 


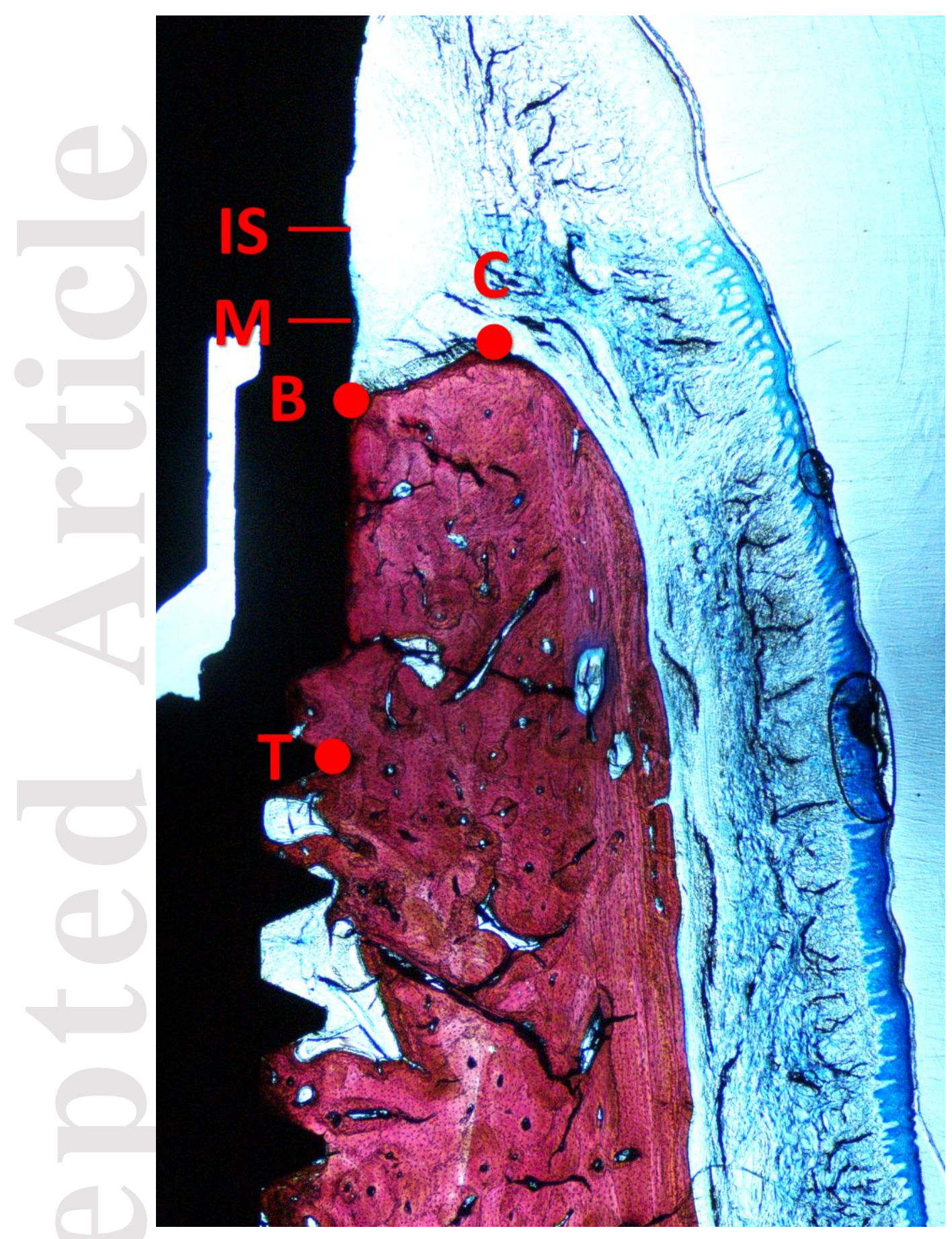

This article is protected by copyright. All rights reserved. 

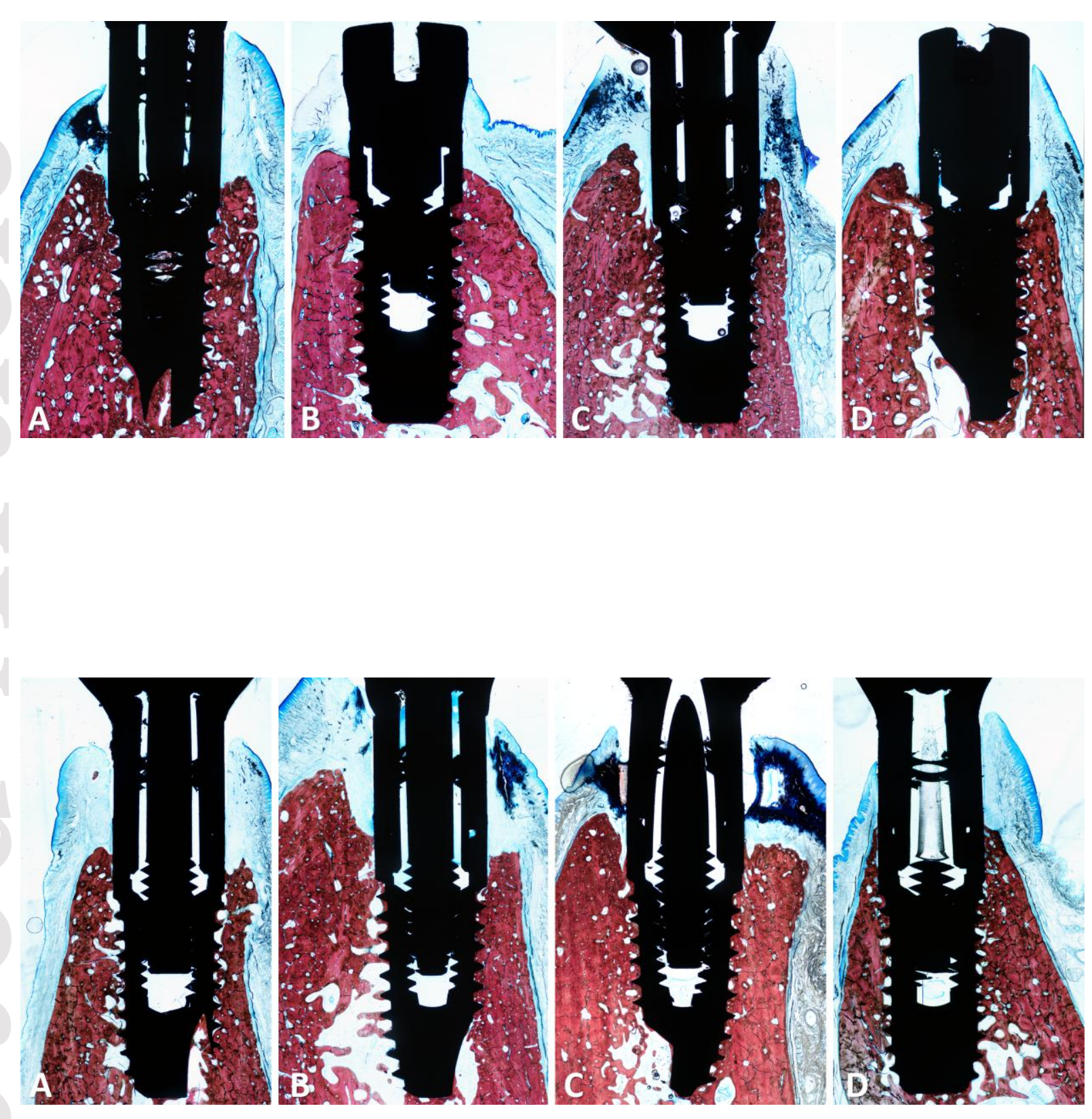

This article is protected by copyright. All rights reserved. 